\title{
SYNTHESIS OF NEW IMMOBILIZED N-CHLORO- SULFONAMIDES AND RELEASE OF ACTIVE CHLORINE FROM THEM
}

\author{
Bohdan Murashevych \\ Department of Biochemistry and Medical Chemistry ${ }^{l}$ \\ Volodymyr Toropin \\ Department of Pharmacy and Technology of Organic Substances ${ }^{2}$ \\ Dmytro Stepanskyi \\ Department of Microbiology, Virology, Immunology and Epidemiology ${ }^{l}$ \\ Hanna Maslak \\ Department of Biochemistry and Medical Chemistry ${ }^{l}$ \\ Kostyantyn Burmistrov \\ Department of Pharmacy and Technology of Organic Substances ${ }^{2}$ \\ Valerii Kotok \\ Department of Processes, Apparatus and General Chemical Technology ${ }^{2}$ \\ Competence center «Ecological technologies and systems» ${ }^{3}$ \\ Vadym Kovalenko $\bowtie$ \\ Department of Analytical Chemistry and Chemical Technology of Food Additives and Cosmetics ${ }^{2}$ \\ Competence center «Ecological technologies and systems»" \\ vadimchem@gmail.com \\ ${ }^{1}$ SI «Dnipropetrovsk Medical Academy of the Ministry of Health of Ukraine» \\ 4 Soborna sq., Dnipro, Ukraine, 49044 \\ ${ }^{2}$ Ukrainian State University of Chemical Technology \\ 8 Gagarina ave., Dnipro, Ukraine, 49005 \\ ${ }^{3}$ Vyatka State University \\ 36 Moskovskaya str., Kirov, Russian Federation, 610000
}

$\triangle$ Corresponding author

\begin{abstract}
A method has been developed for the synthesis of granular polymeric materials with immobilized N-chloro-sulfonamide groups. Commercially available resin polymers widely applied for the preparation of ion exchangers have been used as polymer carriers. The elaborated technological conditions make it possible to modify these resins with a high conversion degree, without deteriorating the strength characteristics, and with the possibility of regulating the concentration of active chlorine over a wide range (up to $11 \% \mathrm{w} / \mathrm{w}$ ). The structure of the synthesized polymers was confirmed by IR spectroscopy data. To determine the concentration of functional groups, a special method of iodometric titration has been developed. The processes of emission of active chlorine from synthesized polymers into aqueous solutions have been studied. It has been shown that this process significantly depends on the composition of the solution: no release of active chlorine into distilled water is observed, and when using tap water, its concentration is reached 5-8 $\mathrm{mg} / \mathrm{dm}^{3}$ and remains up to 30 days when the granules are in water. The processes of activation of active chlorine emission by compounds of amine nature have been studied, the corresponding kinetic curves of the dependence between change in the concentration of active chlorine in solution and the used activator are presented. It has been found that the nature of the used activator strongly affects, among other things, the stability of the obtained chlorine-active solutions. Taurine and sulfamic acid are found to be the optimal activators for obtaining stable solutions of active chlorine of high concentration. The composition of the $\mathrm{N}$-chloro-taurin solution obtained in this way has been additionally analyzed by UV spectroscopy. Thus, the synthesized polymers
\end{abstract}


make it possible to quickly in situ obtain high-purity solutions of active chlorine without the use of special electrochemical equipment. The polymers themselves are compact, stable, and can be repeatedly regenerated.

Keywords: functional polymers, immobilization, N-chloro-sulfonamides, active chlorine, resins, biocides.

DOI: $10.21303 / 2461-4262.2021 .001929$

\section{Introduction}

Active chlorine compounds, of which sodium and calcium hypochlorites, hypochlorous acid, and various chloramines are the most famous, are known as extremely effective biocidal agents [1-3]. Due to their high oxidative and chlorination activity, these compounds effectively neutralize microorganisms, viruses, and prions, in a time inversely proportional to the concentration of active chlorine [4-6]. So, in modern world, consumption and, accordingly, demand for these preparations increases constantly. Hypochlorous acid and some N-chloro-aminoacids, for example, $\mathrm{N}$-chloro-taurine, have an additional advantage, because they are endogenous and therefore do not cause allergic reactions, allowing their application for the treatment of skin surfaces [7-9]. The high efficiency, accessibility and low cost of such preparations determine their widespread use for the disinfection of drinking water, various surfaces, premises, as well as in medicine [10-13]. In particular, $0.1 \%$ sodium hypochlorite is effective against SARS-CoV-2 virus and is recommended by WHO for treating all types of surfaces in order to prevent the spread of COVID-19 [14]. However, most part of traditional active chlorine compounds exist in the form of diluted solutions, which are unstable, corrosive, and require special storage and transportation conditions [15-17]. In situ synthesis of such solutions is possible only via special electrochemical equipment [18-20]. Solid forms of active chlorine, such as chloramines B, T, sodium dichloroisocyanurate, dichlorohydantoin, and others, contain concomitant organic impurities, increase the organic load of the ambient treated, and therefore their use in medicine is limited. Thus, the development of new forms of active chlorine, allowing to expand the scope of its application, is the important task of modern chemistry. The most promising solution of this task is the elaboration of chlorine-containing polymers. This area of modern chemistry of macromolecular compounds has become very relevant in the last decade. By now, a wide range of chlorine-releasing polymers of different forms (resins, fibers and fabrics) and purposes (water and surfaces disinfection, protection against chemical warfare agents, creation of hospital fabrics, etc.) has been described [21-25]. The aim of our investigation consisted in the synthesis of materials with immobilized active chlorine (with exact content of chlorine) on polymer carriers which are specific for Ukraine and the CIS countries. Investigation emission rate of active chlorine, depending on the activation medium, makes it possible to determine the conditions and areas of use these materials.

\section{Materials and methods used for the synthesis and analysis of polymer materials with immobilized N-chloro-sulfonamide groups}

2. 1. Materials and methods used for the synthesis of polymer materials with immobilized N-chloro-sulfonamide groups

Industrially produced granular resins, which are the copolymer of styrene and divinylbenzene of gel or macroporous structures, have been chosen by us as polymer carriers for further modification. These resins are used as the raw materials for the production of ion exchangers, in particular, sulfonic cation exchanger KU-2-8, and therefore are standardized, available, and cheap [26]. The method of immobilization of N-chloro-sulfonamide groups includes successive stages of obtaining sulfochloride, its ammonolisys and chlorination of the resulting amide with sodium hypochlorite; if necessary, the resulting Na-forms of N-chloro-sulfonamides can be converted to $\mathrm{H}$-forms by treatment with hydrochloric acid (Fig. 1).

The synthesis procedure was identical for the resin of both gel and macroporous structure and consisted of the following. The $100 \mathrm{~g}$ sample of initial resin was placed in a glass flask, $800 \mathrm{ml}$ of 1,2-dichloroethane was added and the mixture was left for 12 hours for maximum swelling. Then, $245 \mathrm{~g}$ of freshly distilled chlorosulfonic acid was added to the flask from a dropping funnel with vigorous stirring, maintaining the synthesis temperature in the range of $55-65^{\circ} \mathrm{C}$. 
The sulfochlorination stage lasted about 3 hours. Then the resin was filtered off, washed thoroughly with ice water, and immediately transferred into a flask containing $700 \mathrm{ml}$ of a $15 \%$ ammonia solution cooled to $0^{\circ} \mathrm{C}$. The reaction mass was left under stirring for 8 hours, all the while maintaining the temperature not higher than $10{ }^{\circ} \mathrm{C}$. Then the resin was filtered and transferred into a flask containing such an amount of 3-5\% sodium hypochlorite solution so that a ratio of $0.01 \mathrm{~mol}$ of sodium hypochlorite per $1 \mathrm{~g}$ of the starting resin was reached, and left under stirring for 12 hours. After that, the resin was filtered off, washed several times with distilled water, and dried in air at room temperature.

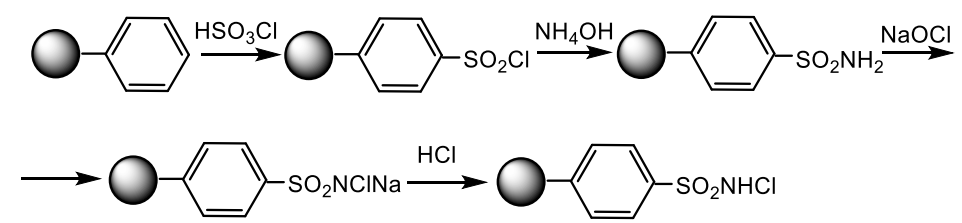

Fig. 1. Synthesis of polymer materials with immobilized N-chloro-sulfonamide groups

If necessary, to obtain the Na-form of immobilized N-chloro-sulfonamide, a sample of the corresponding Na-form of the resin was treated with the excess of the cooled to $0{ }^{\circ} \mathrm{C} 5 \%$ hydrochloric acid solution, filtered off, washed with distilled water and dried in the same way.

\section{2. Materials and methods used in the study of the structure of synthesized polymer materials with immobilized $\mathrm{N}$-chloro-sulfonamide groups}

The nature of the functional groups of the synthesized materials was analyzed by IR spectroscopy. The dried samples of the synthesized polymers were ground in a mortar to fine powders, mixed with a sufficient amount of $\mathrm{KBr}$, and tablets were pressed from the resulting mixture, that then were studied on a Spectrum BX11FT-IR Perkin-Elmer IR spectrometer.

The concentration of immobilized active chlorine was determined by iodometric titration [27] according to the following procedure. A weighed portion of N-chloro-sulfonamide about $1.0 \mathrm{~g}$ mass (precisely weighed sample) was placed in a $250 \mathrm{ml}$ flask with $100 \mathrm{ml}$ of distilled water, then $10 \mathrm{ml}$ of $10 \% \mathrm{KI}$ solution and $10 \mathrm{ml}$ of $10 \% \mathrm{H}_{2} \mathrm{SO}_{4}$ were added, mixing thoroughly after each step. The mixture was slowly heated in the closed flask on a water bath until the release of iodine starts. The released iodine was being titrated with $0.1 \mathrm{~N}$ sodium thiosulfate solution. The heating and titration of the analyzed sample were periodically repeated until the release of iodine into the solution ceases. The concentration of active chlorine $(Y)$ in $\mathrm{mg}$-eq $/ \mathrm{dm}^{3}$ has been calculated by the formula:

$$
Y=\frac{V \cdot 0.003545 \cdot 1000 \cdot 1000}{V_{1}}
$$

where $V$ - the volume of the $0.1 \mathrm{~N}$ solution of sodium thiosulfate, which was used for titration of the analyzed sample, $\mathrm{cm}^{3} ; 0.003545$ - the mass of active chlorine, which corresponds to $1 \mathrm{~cm}^{3}$ of $0.1 \mathrm{~N}$ solution of sodium thiosulfate, $\mathrm{g} ; 1000$ - conversion factor $\mathrm{g} / \mathrm{cm}^{3}$ to $\mathrm{g} / \mathrm{dm}^{3} ; 1000$ - conversion factor $\mathrm{g} / \mathrm{dm}^{3}$ to $\mathrm{mg} / \mathrm{dm}^{3} ; V_{1}$ - the volume of the solution taken for analysis, $\mathrm{cm}^{3}$.

\section{3. Materials and methods used in the study of the release of active chlorine from} synthesized materials

The release of active chlorine has been studied by immersion of the sample of N-chlorosulfonamides immobilized on a polymer carrier into distilled water or water containing activators, followed by determination of the amount of active chlorine emitted into the solution by the standard iodometric titration method [27]. For this, a sample of a polymer about $1.0 \mathrm{~g}$ (about $1 \mathrm{mmol}$ of active chlorine, precisely weighed sample) was placed in a $250 \mathrm{ml}$ flask with $100 \mathrm{ml}$ of distilled water and then the calculated amount of activator $(4-6 \mathrm{mmol})$ was added. The activator was always added in a significant excess to ensure quick and complete release of active chlorine into the solution. 
The contents were thermostated at a temperature of $+20^{\circ} \mathrm{C}$ in a dark place, periodically mixing. At certain time intervals ( $5 \mathrm{~min}, 15 \mathrm{~min}, 30 \mathrm{~min}, 45 \mathrm{~min}, 60 \mathrm{~min}, 120 \mathrm{~min}, 180 \mathrm{~min}$ and $240 \mathrm{~min}-$ for $\mathrm{H}$-forms), the aliquot of $10 \mathrm{ml}$ of the solution was taken, placed in a titration flask with $30 \mathrm{ml}$ of distilled water, then $10 \mathrm{ml}$ of $10 \%$ KI solution and $10 \mathrm{ml}$ of $10 \%$ sulfuric acid solution were added. The mixture was stirred after adding each reagent and kept in a dark place for $3 \mathrm{~min}$. Then the sample was titrated with $0.1 \mathrm{~N}$ sodium thiosulfate solution (when taurine, sulfamic acid and aqueous ammonia were used as activators) or $0.01 \mathrm{~N}$ sodium thiosulfate solution (when ammonium chloride and KU2-8 cation exchanger in ammonium form were used as activators). The concentration of active chlorine in the solution has been calculated by a formula similar to the determination of the concentration of immobilized active chlorine.

\section{Results of the investigation of the structure of synthesized polymers and emission of} active chlorine

3. 1. Structure and properties of the synthesized polymers with immobilized N-chlorosulfonamide groups

Using the method developed by us, granular polymer materials of gel and macroporous structures have been synthesized, the physicomechanical properties of which practically do not differ from the initial polymers. The appearance of these materials is shown in Fig. 2.

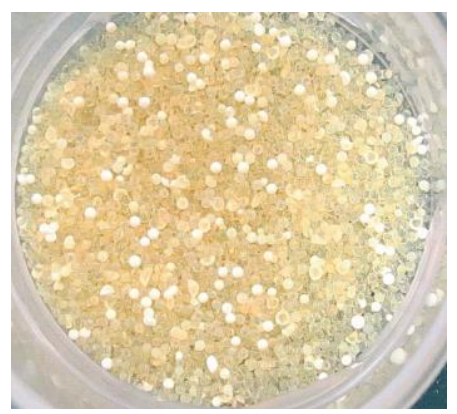

$a$

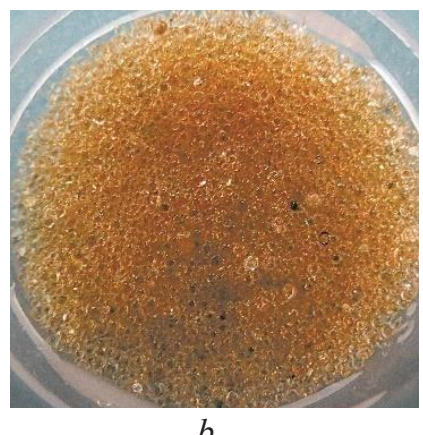

$b$

Fig. 2. The appearance of the synthesized granular polymer materials: $a-\mathrm{N}$-chloro-sulfonamide immobilized on the macroporous matrix; $b$ - N-chloro-sulfonamide immobilized on the gel matrix

The moisture content of air-dried products is $15-25 \%$ mass.

The analysis of the IR spectra of the synthesized polymers confirms the declared structures. IR spectra of Na- and H-forms of polymeric N-chlorosulfonamide are shown in Fig. 3.

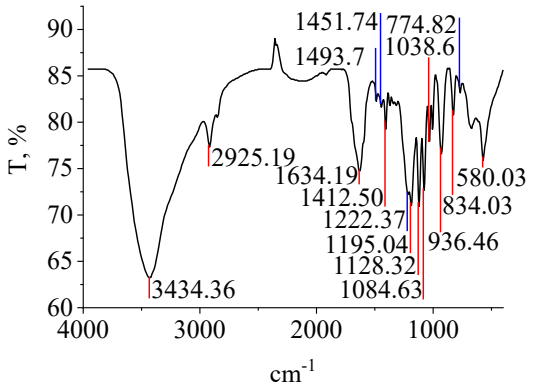

$a$

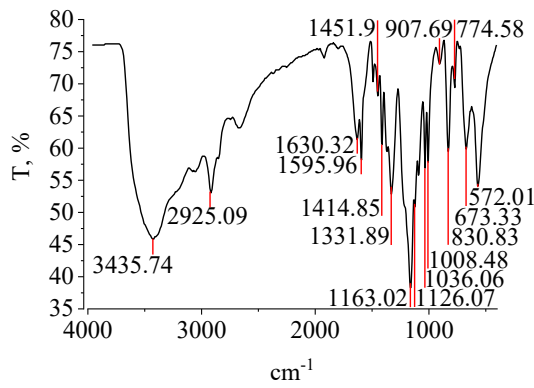

$b$

Fig. 3. IR spectra of immobilized N-chloro-sulfonamides: $a$ - spectrum of N-chlorosulfonamide in Na-form; $\mathrm{b}$ - spectrum of $\mathrm{N}$-chlorosulfonamide in $\mathrm{H}$-form

The stability of the synthesized materials is very high: the loss of active chlorine when stored in a closed jar at room temperature and periodic exposure to direct sunlight is less than $1 \%$ per year. It is incommensurable more than the stability of, for example, sodium hypochlorite [28]. 


\section{2. Release of active chlorine from synthesized polymers with immobilized N-chloro-} sulfonamide groups

The study of the release processes of active chlorine from synthesized polymers has been carried out on samples of sodium N-chloro-sulfonamide of gel and macroporous structure with the active chlorine content of $8.7 \%$ and $8.3 \%$ and moisture content of $20.0 \%$ and $22.8 \%$, respectively, as well as on polymer samples in $\mathrm{H}$-form with the same quantitative characteristics obtained by treating said sodium $\mathrm{N}$-chlorosulfonamides with hydrochloric acid. It has been found that when samples are added into distilled water, the release of active chlorine into the solution is not observed either immediately or during 7 days of storage. At the same time, when they are added into tap water, the concentration of active chlorine of $5-8 \mathrm{mg} / \mathrm{dm}^{3}$ is reached in the solution already in the first hours and remains for a long time (up to 30 days when the resin is in water). But, this concentration is not sufficient for the emergence of powerful microbicidal properties of solutions. To increase the concentration, the activation processes of the synthesized polymers with activator substances have been studied, which have been previously described as effective for N-chloro-sulfonamides of a similar structure [29]. The activator, chemically interacting with the immobilized $\mathrm{N}$-chloro-sulfonamide group, facilitates the cleavage of the $\mathrm{N}-\mathrm{Cl}$ bond in the polymer structure, and is also an acceptor of the emitted active chlorine, forming a new chlorine-active compound, but already in solution. Any compound of amine nature, including amino acids in the composition of the cell membranes of bacteria and nucleic acids of viruses, can serve as activators; this, in particular, explains the antimicrobial activity of industrially produced chloramines. It have been tested as activators the number of ammonia derivatives and organic amines, each of which is capable of forming more or less stable N-chloramines: ammonia solution (ammonium hydroxide), ammonium chloride, KU-2-8 cation exchange resin in ammonium form, sulfamic acid, aminoacetic acid, aminocaproic acid and taurine. The reactions of these compounds with immobilized N-chloro-sulfonamide groups are shown in Fig. 4 in general form.

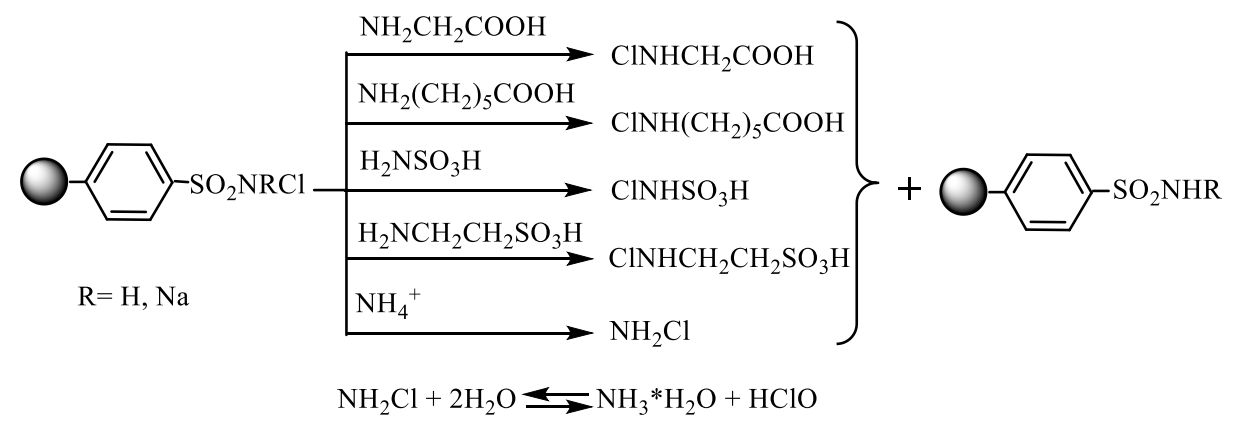

Fig. 4. Activation of the release of immobilized active chlorine into the solution using amine compounds

The results of the experiment are shown in Fig. 5 in the form of kinetic curves of the dependence of the concentration of active chlorine in solution on the used activator and the exposure time.

The stability of the chlorine-active solutions obtained by the activation of synthesized polymers by various activators was analyzed. After activation by the method described above, the resin granules were filtered off, and the obtained solutions were stored in glass bottles at a temperature of $10^{\circ} \mathrm{C}$, periodically determining the concentration of active chlorine in them. Data on the change in the concentration of these solutions in time are shown in Table $\mathbf{1 .}$

As can be seen, the solutions of $\mathrm{N}$-chlorothaurine and $\mathrm{N}$-chlorosulfamic acid are the most stable. The difference in stability is due to different decomposition mechanisms of the obtained active chlorine compounds.

The treatment of all the studied polymers after the end of the experiment with a $3 \%$ solution of sodium hypochlorite led to a concentration of immobilized active chlorine, almost equal to the initial one. This proves the possibility of multiple regenerations of these polymers. 


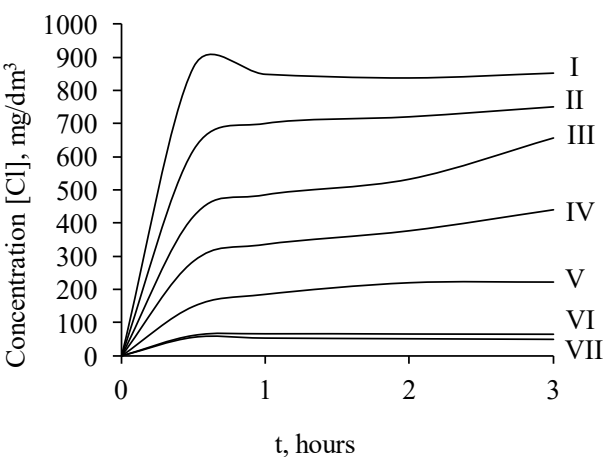

$a$

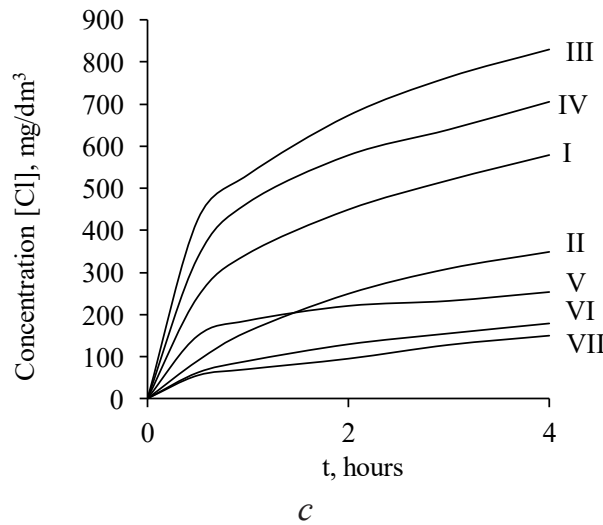

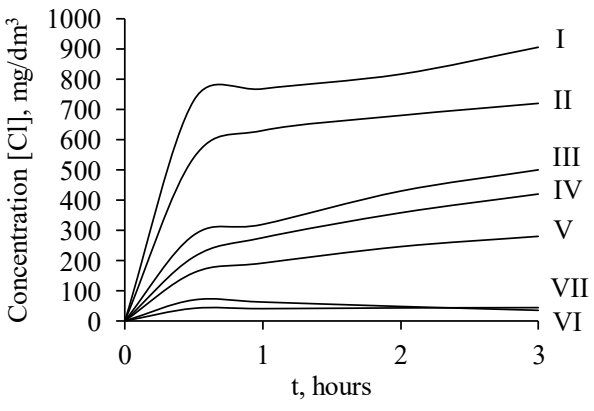

$b$

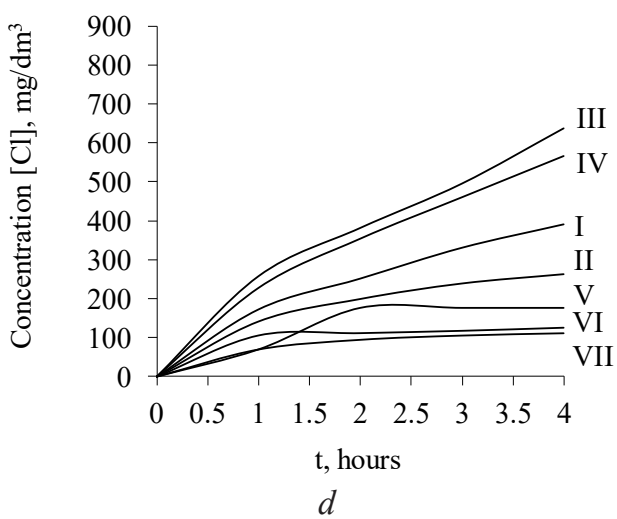

Fig. 5. Kinetic curves of the release of immobilized active chlorine into solution upon activation of synthesized resins by amine activators: $a-\mathrm{N}$-chloro-sulphonamide in Na-form immobilized on the macroporous structure resin; $b-\mathrm{N}$-chloro-sulphonamide in Na-form immobilized on of the structure resin; $c-\mathrm{N}$-chloro-sulphonamide in $\mathrm{H}$-form immobilized on the macroporous structure resin; $d-\mathrm{N}$-chloro-sulphonamide in $\mathrm{H}$-form immobilized on the gel structure resin. Activators: I - taurine $4.6 \mathrm{mmol}$; II - aminoacetic acid

$4.0 \mathrm{mmol}$; III - sulfamic acid $4.1 \mathrm{mmol}$; IV - aminocaproic acid $4.0 \mathrm{mmol}$; V - ammonia solution $6.0 \mathrm{mmol}$ (re-countedon $100 \%$ ); VI - ammonia hydrochloride $4.0 \mathrm{mmol}$; VII - ammonium form of KU-2-8 cation exchanger $5.0 \mathrm{mmol}$

Table 1

Stability of the obtained active chlorine solutions

\begin{tabular}{clcccccc}
\hline \multirow{2}{*}{ No. } & \multirow{2}{*}{ Activator applied } & \multicolumn{5}{c}{ Active chlorine concentration, $\mathbf{~ m g / d m} \mathbf{d m}^{\mathbf{3}}$} \\
\cline { 3 - 7 } & & Initial & $\mathbf{1}^{\text {st }} \mathbf{d a y}$ & $\mathbf{3}^{\text {rd }} \mathbf{d a y}$ & $\mathbf{5}^{\text {th }} \mathbf{d a y}$ & $\mathbf{7}^{\text {th }} \mathbf{d a y}$ & $\mathbf{1 4}^{\text {th }} \mathbf{d a y}$ \\
\hline 1 & Taurine & 8500 & 8409 & 8319 & 8280 & 8207 & 8020 \\
2 & Aminoacetic acid & 7500 & 500 & - & - & - & - \\
3 & Sulphamic acid & 6500 & 6450 & 6420 & 6390 & 6320 & 6270 \\
4 & Aminocaproic acid & 4300 & 2811 & 1056 & 120 & - & - \\
5 & Ammonia solution & 2200 & 65 & 5 & - & - & - \\
6 & Ammonium chloride & 670 & 5 & - & - & -
\end{tabular}

4. Discussion of the results of the investigation of the structure of synthesized polymers and emission of active chlorine

4. 1. Structure and properties of the synthesized polymers with immobilized N-chloro-sulfonamide groups

The developed sulfochlorination technique due to the use of 1,2-dichloroethane as a solvent allows to save a significant amount of chlorosulfonic acid, and the solvent itself can be 
easily regenerated. Especially important is the fact that the optimal ratio of reagents to minimize the formation of undesirable immobilized sulfonic groups has been found. These groups are not active in the next stages of the synthesis and lead to a decrease in the number of target N-chloro-sulfonamide groups. The content of free sulfo groups determined by the standard method [30] does not exceed $0.3 \mathrm{mg}$-eqv/g. The stages of amination and interaction with sodium hypochlorite are highly exothermic, and taking into account that the reaction is heterogeneous, they can lead to local overheating and destruction of the three-dimensional structure of the polymer matrix, which negatively affects the strength characteristics of resins. Our technique allows to avoid these processes.

It has been found that the concentration of immobilized active chlorine is most conveniently regulated at the last stage, namely, by changing the ratio between polymer sulfonamide and sodium hypochlorite. At a ratio of $0.005 \mathrm{~mol}$ of $\mathrm{NaClO}$ per $1 \mathrm{~g}$ of resin, the percentage of active chlorine in the latter is on average $5.1 \%$, and at a ratio of $0.007 \mathrm{~mol}$ of $\mathrm{NaClO}$ per $1 \mathrm{~g}$ of resin it is $7.2 \%$. The optimum ratio is $0.01 \mathrm{~mol}$ of $\mathrm{NaClO}$ per $1 \mathrm{~g}$ of the starting polymer, at which the concentration of active chlorine in both gel and macroporous resins is about $10-11 \%$. The corresponding yield of the target product excluding branching of the polymer unit is $37.4 \%$. The relatively low conversion is most likely due to diffusion and steric difficulties in contact of the reagent with the polymer substrate. It must be emphasized that the developed method for determining the amount of active chlorine in the resin involves periodic heating of the mixture with stirring to provide fast and full release of it from the entire volume of the granule. Accordingly, the titrated solution has a higher temperature and is longer exposed to light than in the standard iodometric titration method. To a certain extent, this contributes to the decomposition of active chlorine; therefore, its actual concentration in the resin may be slightly higher than that obtained from the experiment.

The IR spectroscopy data obtained are obvious enough. It is known that immobilized sodium N-chloro-sulfonamides exist in the form of the sodium salt of N-chloro-sulfoximidic acid, and the corresponding sodium forms exist as the N-chloro-sulfonamides actually (Fig. 6) [31]:
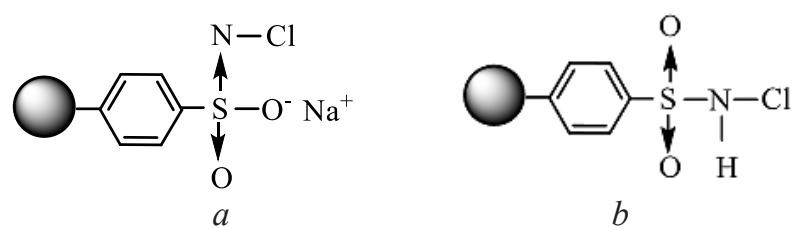

Fig. 6. Structures of the functional groups of $\mathrm{Na}$ - and H-forms of immobilized N-chlorosulfonamides: $a-\mathrm{N}$-chloro-sulfoximidic form; $b-\mathrm{N}$-chloro-sulfonamide form

In the spectra, absorption bands of $1128 \mathrm{~cm}^{-1}$ are observed, which correspond to vibrations of the skeleton of $\mathrm{C}-\mathrm{H}$ bonds of the aromatic cycle due to the presence of an electron-acceptor sulfamide fragment. The absorption band of $834 \mathrm{~cm}^{-1}$ is characteristic of 1,4-disubstituted aryls and confirms the preferred para-position of the sulfamide group in the phenyl fragment. The presence of adsorbed water is evidenced by the diffuse absorption band of average intensity of about $3434 \mathrm{~cm}^{-1}$, which remains even after long-term exposure of the sample in a desiccator over concentrated sulfuric acid. The spectrum of immobilized sodium N-chloro-sulfonamide contains absorption bands of $1222 \mathrm{~cm}^{-1}$ and $1195 \mathrm{~cm}^{-1}$, characteristic of the sulfoximide fragment, while the absorption bands of $1332 \mathrm{~cm}^{-1}$ and $1163 \mathrm{~cm}^{-1}$ in the spectrum of the corresponding H-form confirm the presence of sulfoxide group in it.

4. 2. Investigation of active chlorine emission from the synthesized polymers, and properties of the obtained solutions

The release of active chlorine from a polymeric carrier is obviously a complex combination of a number of heterogeneous and homogeneous reactions proceeding sequentially and parallel: diffusion of the activator to the phase boundary, its chemisorption, chemical reaction of the transfer of active chlorine to the activator molecule, desorption of the reaction product, its diffusion into solution and decay, the mechanism of which may also be different depending on the nature of the 
activator and the $\mathrm{pH}$ of the medium. So, it is only advisable to study the rate of change in the concentration of active chlorine in the solution when using one or another activator, and it is impossible to determine the activation mechanism basing only on kinetic data.

As seen, the use of all activators leads to a significant increase in the concentration of active chlorine in the solution. The release of active chlorine from resins of the gel structure is slower than from resins of the macroporous structure, especially for H-forms of polymers. This allows suggesting the significant effect of diffusion into and from the granule on the overall kinetics of the process, which is facilitated in the macroporous resin due to the presence of a large number of pores. The release of active chlorine from sodium N-chloro-sulfonamides generally occurs faster than from the corresponding $\mathrm{H}$-forms. This can be explained by the formation of the electric double layer around the granule due to dissociation of the O-Na bond of the immobilized groups and requires further studies. The maximum concentration of active chlorine in the solution strongly depends on both the activator used and the nature of the functional group of the polymer. So, over the observed period of time, the maximum concentration $905 \mathrm{mg} / \mathrm{dm}^{3}$ for the Na-form of the resin was achieved with taurine, and in the case of the H-form - with sulfamic acid $\left(830 \mathrm{mg} / \mathrm{dm}^{3}\right)$. The experiment had not been carried out until a certain «equilibrium» concentration of active chlorine in the solution is obtained, because the ultimate goal was to determine a system that allows getting the maximum concentration of the solution in the shortest possible time. Significant concentrations of active chlorine $\left(500-750 \mathrm{mg} / \mathrm{dm}^{3}\right.$ ) are also achieved with the use of amino acids, and in the case of sodium N-chloro-sulfonamides aminoacetic acid leads to a higher concentration, but for $\mathrm{H}$-forms, it is aminocaproic acid. The use of ammonium derivatives as activators allows one to achieve lower (up to $230 \mathrm{mg} / \mathrm{dm}^{3}$ ) concentrations of active chlorine. It should be noted that ammonium chloride and ammonium form of KU-2-8 cation exchanger, in general, are practically similar in their effect on these systems, while they are more active with respect to H-forms of polymers and allow obtaining solutions of about $150 \mathrm{mg} / \mathrm{dm}^{3}$ of active chlorine. This may also be related to the structure of the electric double layer around the granule, because unlike other activators, which are weak electrolytes, these compounds form many ammonium cations in aqueous solutions.

Besides the chemically pure activators mentioned, the processes of activation of active chlorine release have been investigated when multicomponent impurities of biological origin are added to the system (suspensions of yeast fungi, solutions artificially contaminated with bacteria, blood, tea mold, urine, etc.). Due to the impossibility of calculating the molar ratio «activator: activated group», the corresponding kinetic data are not given here. However, the release of active chlorine was noted in all cases by all the studied polymers, and its quantitative characteristics will be determined in further studies.

The experiment has shown that the activation by taurine of the macroporous resin with immobilized N-chloro-sulfonamide groups in the Na-form is most effective for quickly reaching the maximum average concentration of active chlorine $\left(850 \mathrm{mg} / \mathrm{dm}^{3}\right.$ in 30 minutes). Furthermore, this solution is one of the most stable. The obtained solution has studied by UV spectroscopy. In the corresponding spectrum (Fig. 7), there is the absorption band of about $250 \mathrm{~nm}$, characteristic of $\mathrm{N}$-chlortaurine, while the absorption band of about $300 \mathrm{~nm}$, which is characteristic of N, N-dichlorotaurine (which is another possible product of this reaction), is absent $[32,33]$.

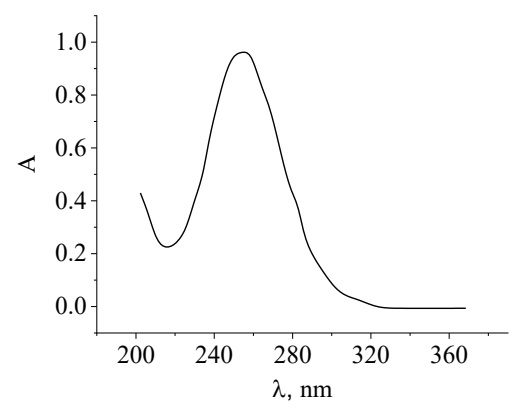

Fig. 7. UV spectrum of the solution obtained by taurine activation of the macroporous resin with immobilized N-chloro-sulfonamide groups in sodium form 
Thus, when using special activators, any synthesized polymer can serve as a source for obtaining chlorine-active solutions. Compared with the classical method of obtaining such solutions by adding an activator to the sodium hypochlorite, this method has several advantages. Firstly, unlike sodium hypochlorite solutions, the synthesized resins are stable and compact. Secondly, they do not contain and do not form after the activation impurities inherent in industrial solutions of sodium hypochlorite (dissolved chlorine, free alkali, sodium chlorate, etc.).

The solution obtained by the activation of polymers with taurine is most interesting in this respect. It is known that $\mathrm{N}$-chlortaurine has a lower oxidative potential than sodium hypochlorite or hypochlorous acid, and respectively has lower antimicrobial activity. But, its cytotoxic effect on different types of cells is also much less, and the tolerance of its high concentrations by the human body is much higher $[8,34]$. In addition, there is evidence of the beneficial effects of chlortaurine and taurine as the product of its decay on the healing rate of open wounds due to inhibition of collagenase [35], antimicrobial [36], and anti-inflammatory [37] effects. Recent studies also show the unique therapeutic properties and good tolerability of N-chlortaurine when inhaled [38]. So, the described method of obtaining the high-purity solution of N-chlortaurine mixed with free taurine may be a promising approach to the new effective pharmaceutical compositions. The features of microbiocidal activity of all synthesized polymers, as well as the chlorine-active solutions generated from them, will be the subject of our separate further studies.

Our results of this investigation do not yet allow to recommend materials for use in the preparation of drinking water in the field, but the high rate of chlorine evolution in the presence of amines indicates that this approach is promising.

\section{Conclusions}

Our method allows obtaining granular polymer materials with immobilized functional groups-donors of active chlorine with the active chlorine content of up to $11 \%$ from available and cheap raw materials. By activating the synthesized polymers with amine activators, pure solutions of chlorine-active compounds can be obtained quite quickly without special conditions. The synthesized polymers are stable, compact, and can be easily regenerated. Unique property of our materials is the ability to obtain pure solutions of N-chlortaurin without admixture of $\mathrm{N}, \mathrm{N}$-dichlortaurin.

\section{Acknowledgements}

This study is supported by the Ministry of Health of Ukraine as part of the research project «Multifunctional polymer materials with powerful antimicrobial properties for antiseptic treatment of wound surfaces and disinfection of air and water» (state registration number 0120U101548). The authors express their gratitude to the Francophone University Agency for financial support of the study as part of the project «Integrated systems for the prevention of viral and bacterial infections based on innovative forms of active chlorine» within the framework of the Plan AUF COVID-19.

\section{References}

[1] Meireles, A., Ferreira, C., Melo, L., Simões, M. (2017). Comparative stability and efficacy of selected chlorine-based biocides against Escherichia coli in planktonic and biofilm states. Food Research International, 102, 511-518. doi: https://doi.org/ 10.1016/j.foodres.2017.09.033

[2] Chien, S.-H., Dzombak, D. A., Vidic, R. D. (2013). Comprehensive Evaluation of Biological Growth Control by Chlorine-Based Biocides in Power Plant Cooling Systems Using Tertiary Effluent. Environmental Engineering Science, 30 (6), $324-332$. doi: https://doi.org/10.1089/ees.2012.0502

[3] Rao, T. S., Nancharaiah, Y. V., Nair, K. V. K. (1998). Biocidal efficacy of monochloramine against biofilm bacteria. Biofouling, 12 (4), 321-332. doi: https://doi.org/10.1080/08927019809378363

[4] Kindermann, J., Karbiener, M., Leydold, S. M., Knotzer, S., Modrof, J., Kreil, T. R. (2020). Virus disinfection for biotechnology applications: Different effectiveness on surface versus in suspension. Biologicals, 64, 1-9. doi: https://doi.org/10.1016/ j.biologicals.2020.02.002

[5] Williams, K., Hughson, A. G., Chesebro, B., Race, B. (2019). Inactivation of chronic wasting disease prions using sodium hypochlorite. PLOS ONE, 14 (10), e0223659. doi: https://doi.org/10.1371/journal.pone.0223659 
[6] Hughson, A. G., Race, B., Kraus, A., Sangaré, L. R., Robins, L., Groveman, B. R. et. al. (2016). Inactivation of Prions and Amyloid Seeds with Hypochlorous Acid. PLOS Pathogens, 12 (9), e1005914. doi: https://doi.org/10.1371/journal.ppat.1005914

[7] Weiss, S., Lampert, M., Test, S. (1983). Long-lived oxidants generated by human neutrophils: characterization and bioactivity. Science, 222 (4624), 625-628. doi: https://doi.org/10.1126/science.6635660

[8] Gottardi, W., Nagl, M. (2010). N-chlorotaurine, a natural antiseptic with outstanding tolerability. Journal of Antimicrobial Chemotherapy, 65 (3), 399-409. doi: https://doi.org/10.1093/jac/dkp466

[9] Bellmann-Weiler, R., Maass, V., Arnitz, R., Weiss, G., Maass, M., Nagl, M. (2018). The endogenous antiseptic N-chlorotaurine irreversibly inactivates Chlamydia pneumoniae and Chlamydia trachomatis. Journal of Medical Microbiology, 67 (9), 1410-1415. doi: https://doi.org/10.1099/jmm.0.000815

[10] Wongkietkachorn, A., Surakunprapha, P., Wittayapairoch, J., Wongkietkachorn, N., Wongkietkachorn, S. (2020). The Use of Hypochlorous Acid Lavage to Treat Infected Cavity Wounds. Plastic and Reconstructive Surgery - Global Open, 8 (1), e2604. doi: https://doi.org/10.1097/gox.0000000000002604

[11] Rutala, W. A., Weber, D. J. (1997). Uses of inorganic hypochlorite (bleach) in health-care facilities. Clinical Microbiology Reviews, 10 (4), 597-610. doi: https://doi.org/10.1128/cmr.10.4.597-610.1997

[12] Sun, S.-H., Kim, S.-J., Kwak, S.-J., Yoon, K.-S. (2012). Efficacy of Sodium Hypochlorite and Acidified Sodium Chlorite in Preventing Browning and Microbial Growth on Fresh-Cut Produce. Preventive Nutrition and Food Science, 17 (3), $210-216$. doi: https://doi.org/10.3746/pnf.2012.17.3.210

[13] Wilhelm, N., Kaufmann, A., Blanton, E., Lantagne, D. (2017). Sodium hypochlorite dosage for household and emergency water treatment: updated recommendations. Journal of Water and Health, 16 (1), 112-125. doi: https://doi.org/10.2166/wh.2017.012

[14] Cleaning and disinfection of environmental surfaces in the context of COVID-19: interim guidance (2020). World Health Organization.

[15] Pişkin, B., Türkün, M. (1995). Stability of various sodium hypochlorite solutions. Journal of Endodontics, 21 (5), $253-255$. doi: https://doi.org/10.1016/s0099-2399(06)80991-x

[16] Gaur, B., Singh, A. K., Rao, N. J. (1994). Corrosion of mild steel in hypochlorite solution - An electrochemical and weightloss study. Indian Journal of Chemical Technology, 1, 225-229.

[17] Active chlorine released from sodium hypochlorite (Assesment Report). Regulation (EU) No 528/2012 concerning the making available on the market and use of biocidal products (2017).

[18] Matousek, R. (2014). Hypochlorite Synthesis Cells and Technology, Sea Water. Encyclopedia of Applied Electrochemistry, 1066-1070. doi: https://doi.org/10.1007/978-1-4419-6996-5_295

[19] Ghalwa, N. A., Tamos, H., ElAskalni, M., El Agha, A. R. (2012). Generation of sodium hypochlorite (NaOCl) from sodium chloride solution using $\mathrm{C} / \mathrm{PbO} 2$ and $\mathrm{Pb} / \mathrm{PbO} 2$ electrodes. International Journal of Minerals, Metallurgy, and Materials, 19 (6), 561-566. doi: https://doi.org/10.1007/s12613-012-0596-0

[20] Migliarina, F., Ferro, S. (2014). A Modern Approach to Disinfection, as Old as the Evolution of Vertebrates. Healthcare, 2 (4), 516-526. doi: https://doi.org/10.3390/healthcare2040516

[21] Kamaruzzaman, N. F., Tan, L. P., Hamdan, R. H., Choong, S. S., Wong, W. K., Gibson, A. J. et. al. (2019). Antimicrobial Polymers: The Potential Replacement of Existing Antibiotics? International Journal of Molecular Sciences, 20 (11), 2747. doi: https://doi.org/10.3390/ijms20112747

[22] Huang, K.-S., Yang, C.-H., Huang, S.-L., Chen, C.-Y., Lu, Y.-Y., Lin, Y.-S. (2016). Recent Advances in Antimicrobial Polymers: A Mini-Review. International Journal of Molecular Sciences, 17 (9), 1578. doi: https://doi.org/10.3390/ijms17091578

[23] Maddah, B. (2014). Anti-bacterial Activity of N-halamin in Hospital Fabrics: New Synthesis Approach and Examination of Anti-Bacterial Characteristics. Journal of Life Science and Biomedicine, 4 (6), 575-578.

[24] Choi, J., Moon, D. S., Ryu, S. G., Lee, B., Ying, W. B., Lee, K. J. (2018). N-chloro hydantoin functionalized polyurethane fibers toward protective cloth against chemical warfare agents. Polymer, 138, 146-155. doi: https://doi.org/10.1016/ j.polymer.2018.01.066

[25] Huang, C., Chen, Y., Sun, G., Yan, K. (2019). Disinfectant Performance of a Chlorine Regenerable Antibacterial Microfiber Fabric as a Reusable Wiper. Materials, 12 (1), 127. doi: https://doi.org/10.3390/ma12010127

[26] Zubakova, L. B., Tevlina, A. S., Davankov, A. B. (1978). Sinteticheskie ionoobmennye materialy. Moscow: Himiya, 184.

[27] Carlos, N. J., Cintia, M. R. (2013). A new simple and practical method for establish available chlorine. Analytical Chemistry: An Indian Journal, 12 (11), 415-422.

[28] Clarkson, R., Moule, A., Podlich, H. (2001). The Shelf-Life of Sodium Hypochlorite Irrigating Solutions. Australian Dental Journal, 46 (4), 269-276. doi: https://doi.org/10.1111/j.1834-7819.2001.tb00291.x

[29] Mashkovskiy, M. D. (1988). Lekarstvennye sredstva. Vol. 2. Moscow: Medicine, 576.

[30] Michaud, C. F. (2011). Defining Ion Exchange Capacity. WC\&P. 
[31] Bogochek, R., Kotsiolek-Balyaveyder, E. (1987). Kationity s hloriruyuschimi, okislitel'nymi i bakteritsidnymi svoystvami. Vysokomolekulyarnye soedineniya, 29 (11), 2346-2352. Available at: http://polymsci.ru/static/Archive/1987/VMS_1987_ T29_11/VMS_1987_T29_11_2346-2352.pdf

[32] Stelmaszynsky, T., Zgliczynski, J. M. (1974). Myeloperoxidase of Human Neutrophilic Granulocytes as Chlorinating Enzyme. European Journal of Biochemistry, 45 (1), 305-312. doi: https://doi.org/10.1111/j.1432-1033.1974.tb03555.x

[33] Thomas, E. L., Jefferson, M. M., Grisham, M. B. (1982). Myeloperoxidase-catalyzed incorporation of amines into proteins: role of hypochlorous acid and dichloramines. Biochemistry, 21 (24), 6299-6308. doi: https://doi.org/10.1021/bi00267a040

[34] Klamt, F., Shacter, E. (2005). Taurine Chloramine, an Oxidant Derived from Neutrophils, Induces Apoptosis in Human B Lymphoma Cells through Mitochondrial Damage. Journal of Biological Chemistry, 280 (22), 21346-21352. doi: https://doi.org/ 10.1074/jbc.m501170200

[35] Fitzgerald, D. J., Fitzgerald, G. A. (1989). Role of thrombin and thromboxane A2 in reocclusion following coronary thrombolysis with tissue-type plasminogen activator. Proceedings of the National Academy of Sciences, 86 (19), 7585-7589. doi: https://doi.org/ 10.1073/pnas.86.19.7585

[36] Gottardi, W., Debabov, D., Nagl, M. (2013). N-Chloramines, a Promising Class of Well-Tolerated Topical Anti-Infectives. Antimicrobial Agents and Chemotherapy, 57 (3), 1107-1114. doi: https://oi.org/10.1128/aac.02132-12

[37] Park, E., Schuller-Levis, G., Quinn, M. R. (1995). Taurine Chloramine Inhibits Production of Nitric Oxide and TNF-alpha in Activated RAW 264.7 Cells by Mechanisms That Involve Transcriptional and Translational Events. Journal of Immunology, 154 (9), 4778-4784.

[38] Arnitz, R., Stein, M., Bauer, P., Lanthaler, B., Jamnig, H., Scholl-Bürgi, S. et. al. (2018). Tolerability of inhaled N-chlorotaurine in humans: a double-blind randomized phase I clinical study. Therapeutic Advances in Respiratory Disease, 12, 175346661877895. doi: https://doi.org/10.1177/1753466618778955

Received date 26.03.2021

Accepted date 06.06.2021

Published date 23.07.2021
(C) The Author(s) 2021

This is an open access article under the Creative Commons CC BY license

How to cite: Murashevych, B., Toropin, V., Stepanskyi, D., Maslak, H., Burmistrov, K., Kotok, V., Kovalenko, V. (2021). Synthesis of new immobilized n-chloro-sulfonamides and release of active chlorine from them. EUREKA: Physics and Engineering, 4, 3-13. doi: https://doi.org/10.21303/2461-4262.2021.001929 